\title{
Comparison of Single Incision and Conventional Laparoscopic Surgery for Surgical Sterilization
}

\author{
Yetkin KARASU1, Duygu KAVAK COMERT² \\ Ankara, Turkey
}

\section{ABSTRACT}

OBJECTIVE: To compare the intraoperative characteristics and postoperative pain levels of single incision and conventional laparoscopic surgeries performed for surgical sterilization.

STUDY DESIGN: A single center prospective observational study was conducted to compare the conventional and single incision laparoscopic partial salpingectomies performed for surgical tubal sterilization. In total of 110 women, 62 in the conventional laparoscopy and 48 in the single incision laparoscopic surgery group participated in the study. The main outcome measures were peritoneal entry time, total operation time, amount of bleeding, intraoperative complications, post-operative pain scores, additional analgesic requirements, and length of hospital stay. Statistical analysis was accomplished using the chisquare test or Mann Whitney $U$ test, where appropriate.

RESULTS: Demographical findings did not differ between the two groups $(p>0.05)$. Similarly, total operation time, rates of intraoperative complications, conversion to laparotomy, length of hospital stay, pre and postoperative hematocrit levels were not significantly different between the groups. Peritoneal entry time was shorter in the single incision laparoscopic group ( $7.1 \mathrm{~min}$. vs. $4.8 \mathrm{~min}$., $p<0.001)$. Additional analgesic requirements, postoperative pain scores in the recovery room and at $6^{\text {th }}, 12^{\text {th }}$, and $24^{\text {th }}$ hours were not different between the groups $(p>0.05)$.

CONCLUSION: Single incision laparoscopic surgery seems a safe and feasible alternative to conventional laparoscopy for surgical tubal sterilization.

Keywords: Partial salpingectomy, Tubal ligation, Contraception, Surgical sterilization, Single Incision laparoscopy

Gynecol Obstet Reprod Med 2018;24(0):22-26

\section{Introduction}

Laparoscopic sterilization techniques include electro-surgical dissection, mechanic obstruction (silicon-band, clips), and partial or complete salpingectomy.

Single incision laparoscopic surgery (SILS) was first de-

${ }^{1}$ Obstetrics and Gynecology University of Health sciences Ankara Training and Research Hospital, Ankara

2 Osman Gazi University Faculty of Medicine Obstetrics and Gynecology, Eskişehir.

Address of Correspondence: Yetkin Karasu

Obstetrics and Gynecology, University of

Health sciences Ankara Training and

Research Hospital 06340 Altındag,

Ankara, Turkey

dr.yetkinkarasu@gmail.com

Submitted for Publication: $\quad$ 07.11.2017

Accepted for Publication: $\quad$ 18.11.2017

\begin{tabular}{|c|c|}
\hline \multicolumn{2}{|c|}{ Access this article online } \\
\hline 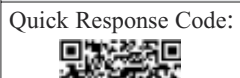 & $\begin{array}{l}\text { Website: www.gorm.com.tr } \\
\text { e- mail: info@gorm.com.tr }\end{array}$ \\
\hline 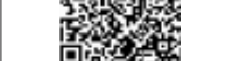 & DOI:10.21613/GORM.2017.750 \\
\hline
\end{tabular}

How to cite this article: Karasu Y. and Kavak Comert D. Comparison of Single Incision and Conventional Laparoscopic Surgery for Surgical Sterilization. Gynecol Obstet Reprod Med 2018;24(1):22-26 scribed in 1976 by Wheeless as a minimally invasive method requiring a single incision for telescope introduction into the peritoneal cavity $(1,2)$. Currently, it is also preferred for major gynecological operations. In addition, minimally invasive surgical techniques are preferred more often to ensure better cosmetic results. Therefore, SILS may be an appropriate alternative to conventional laparoscopy for surgical sterilization.

Our aim was to compare the intraoperative characteristics and postoperative pain levels of single incision and conventional laparoscopic surgeries performed for surgical sterilization.

\section{Material and Method}

This prospective observational study was conducted between October 2014 - April 2016. Institutional ethics committee approved the study and all participants gave informed consent. The study included the women admitting for surgical tubal sterilization. Eligible women received brief information about the study and the two surgical techniques. Women with contraindications for general anesthesia or laparoscopic surgery were excluded. In the conventional laparoscopy group, pneumoperitoneum was created using a Veress needle following appropriate cleansing, sterile coverings and urinary 
catheterization. The camera port (12 mm) was inserted through a $1 \mathrm{~cm}$ intra-umbilical horizontal incision. A steep $30^{\circ}$ Trendelenburg position was always obtained. Two $5 \mathrm{~mm}$ accessory ports were inserted after the patients were positioned in the Trendelenburg position. In the SILS group we used a Covidien SIISTM port (Tyco Healthcare Pty Ltd, Lane Cove, NSW) and placed it according to the manufacturer's instructions through a $2 \mathrm{~cm}$ intra-umbilical horizontal incision. Then, the $12 \mathrm{~mm}$ camera port and two $5 \mathrm{~mm}$ accessory ports were inserted through the port. Following abdominal exploration, women were positioned into $30^{\circ}$ Trendelenburg position. In all patients a mid-tubal $1 \mathrm{~cm}$ portion of the fallopian tubes was dissected and removed. Bipolar electrocoagulation device and cold scissor were used for tissue dissection. We used the same rigid, conventional laparoscopic instruments in both groups. At the end of the surgery, fascial openings larger than $10 \mathrm{~mm}$ were sutured using \#0 polyglactin 910 (Vicryl, Ethicon, USA), and the skin incisions were closed using a 3.0 polyprolene (Prolene, Ethicon, USA) suturing material. Laparoscopic entry time, total operation time, amount of bleeding, and intraoperative complications were recorded in both groups. The laparoscopic entry time (suet up) was included the duration from the first skin incision to the insertion of all trocars and laparoscopic instruments. Mean hematocrit was assessed at the postoperative $6^{\text {th }}$ hour and compared with the preoperative levels. Postoperative pain was evaluated after the patients were transported to the recovery room and at the $6^{\text {th }}, 12^{\text {th }}$, and 24 th postoperative hours. For pain evaluation, a five-step, $10 \mathrm{~cm}$ long visual analog pain assessment scale (VAS) was used. Pain scores were assessed and recorded by the obstetrics and gynecology residents responsible for the postoperative care. All participants received a $25 \mathrm{mg}$ dose of dexketoprofen (Deksaljin 50 mg/amp, Nobel Pharmaceutical, Istanbul, Turkey) I.M., following the operation after wakening and a $25 \mathrm{mg}$ dose of dexketoprofen tablet (Deksaljin $25 \mathrm{mg}$, Nobel Pharmaceutical, Istanbul, Turkey) orally every 12 hours. Women requiring an additional dose received an additional $25 \mathrm{mg}$ dexketoprofen (Deksaljin $50 \mathrm{mg} / \mathrm{amp}$, Nobel Pharmaceutical, Istanbul, Turkey) administered I.M. This dose was recorded as "additional analgesic dose". All patients were hospitalized at least 24 hours following the surgery for pain evaluation.
Statistical analysis was performed using the SPSS 17 statistics package software. A $p$ value of $<0.05$ was considered statistically significant. Non-parametric categorical variables were analyzed with the chi-square test; continuous variables were analyzed with Student's t and Mann Whitney tests, according to the distribution of the variable.

\section{Results}

The study included 110 women who applied for surgical tubal sterilization and 62 and 48 of the women were operated using conventional and SILS, respectively (Figure 1). Table 1 summarizes the demographics of the participants. Although the two groups differed in terms of number of pregnancies and abortions, the groups were similar in terms of age, body mass index (BMI), and number of deliveries. The groups were also similar in terms of the type of previous deliveries.

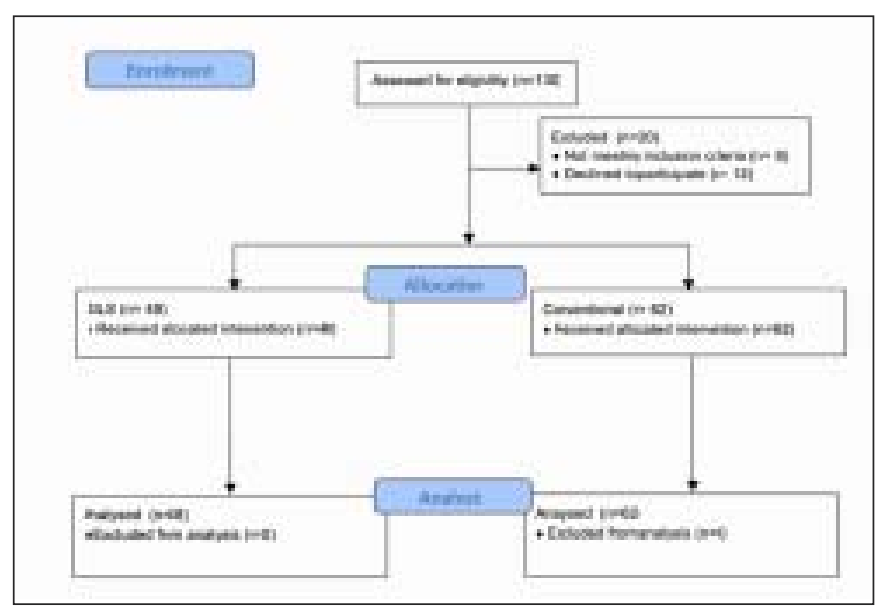

Figure 1: Patient enrollment

The mean laparoscopic entry time was significantly shorter in the SILS group (4.8 minutes) in comparison with the conventional laparoscopy group (7.1 minutes), $(p<0.001)$. However, the total operation time was similar $(p=0.190)$.

One patient in the conventional laparoscopy group had injury of the inferior epigastric artery while inserting the right

Table 1: Demographic characteristics of the women operated using conventional and SILS for tubal sterilization

\begin{tabular}{|c|c|c|c|}
\hline & Conventional $(n=62)$ & SILS $(n=48)$ & $p$ value \\
\hline Age (years) (mean) ( $\pm S D)$ & $34.7( \pm 3,26)$ & $36.1( \pm 3,45)$ & $0.055 \ddagger$ \\
\hline Gravidity (median) (min-max) & $4(1-6)$ & $4(2-11)$ & $0.031 \ddagger$ \\
\hline Parity (median) (min-max) & $3(1-6)$ & $3(2-8)$ & $0.722 \ddagger$ \\
\hline Abortion (median) (min-max) & $0(0-4)$ & $1(0-4)$ & $0.005 \ddagger$ \\
\hline BMI $\left(\mathrm{kg} / \mathrm{m}^{2}\right)$ (mean) $( \pm S D)$ & $24.9( \pm 3,80)$ & $25.1( \pm 2,82)$ & $0.267 \ddagger$ \\
\hline \multicolumn{4}{|l|}{ Mode of previous deliveries } \\
\hline Vaginal & $45(72.6 \%)$ & $33(68.8 \%)$ & \multirow{2}{*}{$0.661 \S$} \\
\hline Caesarean section & $17(27.4 \%)$ & $15(31.3 \%)$ & \\
\hline
\end{tabular}

‡: Mann-Whitney U-test. §: Chi-square test. BMI: Body mass index. $\pm S D$ : Standard deviation. Min-max: Minimum-maximum values 
accessory port. The port was removed, and the bleeding was controlled with a transabdominal suture. Other than this case, no intraoperative complications occurred in either group. All patients had minimal bleeding. Pre-and postoperative hematocrit levels did not differ in both groups $(p>0.05)$. The hospital stay was not different in both groups ( $p>0.05$, Table 2$)$. In the SILS group, three patients had serous discharge from the intra-umbilical incision during the postoperative period. However, there was not any bacterial growth in the wound cultures. Umbilical discharge ceased after daily dressing.

The groups had similar VAS scores immediately after patients' transport to a recovery room (initial assessment), and at the $6^{\text {th }}, 12^{\text {th }}$ and $24^{\text {th }}$ hours (Table 3 ). In addition, the comparison of the frequency of nausea, vomiting and shoulder pain ( $p=0.515 ; p=0.855 ; \mathrm{p}=0.429$, respectively) did not differ between groups. Moreover, additional postoperative analgesic requirements were similar $(p=0.739)$.

\section{Discussion}

In our study, mean operation time, mean hematocrit change, complication rate, mean length of hospital stay were similar in SILS and conventional laparoscopy groups. Mean laparoscopic entry time was shorter in the SILS group. In addition, post-surgical pain levels and the amount of additional analgesic use were similar.

In the literature, there are studies comparing gasless single incision and conventional laparoscopy for surgical sterilization $(3,4)$. However, to our knowledge, this study is the first that compares single incision laparoscopy using a port system and conventional laparoscopic surgical sterilization. The strength of our study is that it compares intraoperative and postoperative variables prospectively for the first time in the literature.

One of the main advantages of SILS is the cosmetic result of the surgery. Although we did not compare the groups in terms of their aesthetic satisfaction levels after the operation, there are studies showing better aesthetic results with SILS (58 ). In addition, long-term pain scores and the contraceptive efficacy of the procedure were not assessed in our study.

Single incision laparoscopic surgery is mostly considered as a difficult procedure for the beginners. Particularly, practitioners can hardly manipulate the laparoscopic instruments introduced almost parallel through the narrow gap of the single port. Nonetheless, as stated by Filho et al. (2), there is a rapid learning curve for SILS among surgeons familiar with conventional laparoscopy. Triangulation can be performed more easily with laparoscopic tools with angles or articulations designed for SILS. However, in our study, we used rigid conventional laparoscopic instruments. Depending on the findings of our study, we can argue that angulated instrument use is not mandatory especially for single port partial salpingectomy using electro surgery.

Many types of operations can now be performed with SILS in the field of gynecology. Although most of the publications are case series and presentations, many authors reported similar intraoperative complication rates of SILS, in comparison with the conventional laparoscopic surgery. Thus, the feasibility and safety of SILS, even for more difficult and complicated procedures gynecological operations, have been widely accepted. (9-13). In addition, most of the complications of conventional laparoscopy occur during Veress needle

Table 2: Comparison of operative findings

\begin{tabular}{llcr}
\hline & Conventional $(\mathrm{n}=62)$ & SILS $(\mathrm{n}=48)$ & $p$ value \\
\hline value & & & \\
Mean Laparoscopic Entry Time (min.) $( \pm \mathrm{SD})$ & $6.96( \pm 2.89)$ & $4.85( \pm 1.45)$ & $<0.001 \ddagger$ \\
Mean Operation Time (min.) $( \pm \mathrm{SD})$ & $39.1( \pm 12.04)$ & $37.2( \pm 8.43)$ & $0.190 \ddagger$ \\
Mean Hematocrit Change (\%) $( \pm \mathrm{SD})$ & $2.35( \pm 2.02)$ & $2.43( \pm 2.44)$ & $0.491 \ddagger$ \\
Mean Length of Hospital-Stay (days) $( \pm \mathrm{SD})$ & $1.56( \pm 0.49)$ & $1.45( \pm 0.50)$ & $0.271 \ddagger$ \\
Conversion to Laparotomy \% & 0 & 0 & $\mathrm{NA}$ \\
\hline
\end{tabular}

‡ Mann-Whitney U-test. $\pm S D$ : Standard deviation

Table 3: Comparison of postoperative pain scores and additional analgesic requirement

\begin{tabular}{lccc}
\hline Postoperative pain scores (mean) $( \pm S D)$ & Conventional $(n=62)$ & SILS $(n=48)$ & $p$ value \\
\hline Initial (recovery room) & $7.12( \pm 1.26)$ & $6.79( \pm 1.35)$ & $0.506 \ddagger$ \\
6th hour & $3.71( \pm 0.80)$ & $4.04( \pm 1.20)$ & $0.119 \ddagger$ \\
$12^{\text {th }}$ hour & $2.65( \pm 0.95)$ & $2.46( \pm 0.85)$ & $0.279 \ddagger$ \\
$24^{\text {th }}$ hour & $1.77( \pm 1.02)$ & $1.58( \pm 0.82)$ & $0.373 \ddagger$ \\
Additional analgesic dose (ampule) & $1.81( \pm 0.82)$ & $1.02( \pm 0.40)$ & 0.739 \\
\hline
\end{tabular}

‡ Mann-Whitney U-test. $\pm S D$ : Standard deviation 
and port entry (10). In contrary, SILS is an open access technique that may decrease the risk of vascular or visceral injury.

One of the goals of applying minimal access techniques is to obtain lower, even the least, postoperative pain levels. Incisional wound site and size contribute to the severity of postoperative pain (14). Therefore, SILS reduces the number of port entries and also might prevent possible nerve injury because the accessory ports are not used in SILS. There are reports about postoperative pain in adnexal masses treated with SILS. While some studies have reported acute postoperative pain that is lower with single port laparoscopy, the results are controversial. Yoon et al. (6) compared SILS with conventional laparoscopy for surgery of adnexal pathologies and reported that postoperative pain was similar in both groups. Sorensen et al. (15) also found that postoperative pain in the 6 th and $24^{\text {th }}$ hours were similar in both groups, but the shoulder tip pain was greater in the SILS group. They stated that this finding might be due to longer operation times in SILS (conventional: 31 minutes, SILS: 42 minutes). Eom et al. (16) reported that SILS had less pain only at the postoperative 2 nd hour, and there was no difference between the two groups regarding postoperative pain at the $4^{\text {th }}, 6^{\text {th }}, 12^{\text {th }}, 24^{\text {th }}, 48^{\text {th }}$ and $72^{\text {nd }}$ hours. On the other hand, Kim et al. (17) found a lower pain score at 24 hours in the SILS group in a study of adnexal pathologies. Fagotti et al. (18) stated that postoperative pain and additional analgesic requirements were lower in the SILS group. Postoperative pain scores and additional analgesic requirements were not different in our study. The reasons underlying this finding can be listed as minor surgical intervention performed, short operative times and occurrence of any complications.

Intraoperative bleeding is an indicator of operative morbidity. In our study the amounts of intraoperative bleeding were also similar in both groups. Ulker et al. (3) reported similar intraoperative hematocrit changes in the gasless single incisional and the conventional laparoscopic surgical sterilization groups. However, there are differences in other studies. Cho et al. (19) compared data from 33 patients treated with SILS and 30 patients treated with conventional laparoscopy for ovarian cysts. They reported that the decline in hemoglobin levels was significantly greater in the SILS group versus the conventional laparoscopy group. Kim et al. (20) compared the results of salpingectomy in tubal pregnancies performed with SILS or multi-port laparoscopy, and found similar hemoglobin levels in both groups. Similarly, we also observed similar changes of hematocrit levels in our study groups. Variations in study populations, conditions and operative procedures might be the reason of the inconsistent results.

In this study, we did not observe any intraoperative complication in the SILS group. In the conventional laparoscopy group, one patient had injury of the inferior epigastric artery during insertion of the right accessory port. Consistent with the literature, no patients required conversion to laparotomy
$(2,21,22)$. A previous study also reported no difference between SILS and conventional laparoscopy in terms of intraoperative complications (23).

In our study, we observed serous discharge from the umbilical incision site in three patients postoperatively. These patients showed no signs of infection, and there was no bacterial growth in the wound cultures. The patients were treated as outpatients with daily changes in the dressing without antibiotics. Therefore, we did not consider these conditions to be a surgical complication.

In conclusion, SILS seems a safe and feasible method for laparoscopic surgical sterilization. Due to the better cosmetic results, it may be an alternative option to conventional laparoscopic sterilization.

\section{:The authors declare no conflicts of interest.}

\section{References}

1. Tasdemir N, Abali R, Celik C, Aksu E, Akkus D. Singleincision-two port laparoscopic tubal ligation: A cost comparison and technique description. J Turk Ger Gynecol Assoc 2015;16(1):30-1.

2. Santos Filho AS, Noviello MB, Damasceno RC, Patricio Edo C, Felix LR, Giostri PG, et al. Single-site laparoscopy in gynecology: preliminary study of a series of 50 cases. Rev Assoc Med Bras 2014;60(6):548-54.

3. Ulker K, Huseyinoglu U. Comparison of tubal sterilization procedures performed by keyless abdominal rope-lifting surgery and conventional CO2 laparoscopy: a case controlled clinical study. TheScientificWorldJournal 2013;2013:963615.

4. Guido RS, Brooks K, McKenzie R, Gruss J, Krohn MA. A randomized, prospective comparison of pain after gasless laparoscopy and traditional laparoscopy. The Journal of the American Association of Gynecologic Laparoscopists 1998;5(2):149-53.

5. Song T, Kim MK, Kim ML, Yoon BS, Seong SJ. Would fewer port numbers in laparoscopy produce better cosmesis? Prospective study. J Minim Invasive Gynecol 2014; 21(1):68-73.

6. Yoo EH, Shim E. Single-port access compared with threeport laparoscopic adnexal surgery in a randomized controlled trial. J Int Med Res 2013;41(3):673-80.

7. Fader AN, Levinson KL, Gunderson CC, Winder AD, Escobar PF. Laparoendoscopic single-site surgery in gynaecology: A new frontier in minimally invasive surgery. J Minim Access Surg 2011;7(1):71-7.

8. Song T, Cho J, Kim TJ, Kim IR, Hahm TS, Kim BG, et al. Cosmetic outcomes of laparoendoscopic single-site hysterectomy compared with multi-port surgery: randomized controlled trial. J Minim Invasive Gynecol 2013;20(4): 460-7. 
9. Jennings AJ, Spencer RJ, Hanks L, Barroilhet L, Kushner D, Rose S, et al. The Feasibility and Safety of Adopting Single-incision Laparoscopic Surgery into Gynecologic Oncology Practice. J Minim Invasive Gynecol. J Minim Invasive Gynecol 2016;23(3):358-63.

10. Dursun P, Caglar M, Akilli H, Ayhan A. Large conization and laparoendoscopic single-port pelvic lymphadenectomy in early-stage cervical cancer for fertility preservation. Case Rep Surg 2013;2013:207191.

11. Iacoponi S, De Santiago J, Diestro MD, Hernandez A, Zapardiel I. Single-port laparoscopic extraperitoneal paraaortic lymphadenectomy. Int J Gynecol Cancer 2013;23 (9):1712-6.

12. Boruta DM, 2nd, Growdon WB, Schorge JO. Single-incision laparoscopic staging for endometrial cancer. J Am Coll Surg 2011;212(1):e1-5.

13. Fagotti A, Boruta DM, 2nd, Scambia G, Fanfani F, Paglia A, Escobar PF. First 100 early endometrial cancer cases treated with laparoendoscopic single-site surgery: a multicentric retrospective study. Am J Obstet Gynecol 2012; 206(4):353 e1-6.

14. Kalkman CJ, Visser K, Moen J, Bonsel GJ, Grobbee DE, Moons KG. Preoperative prediction of severe postoperative pain. Pain 2003;105(3):415-23.

15. Hoyer-Sorensen C, Vistad I, Ballard K. Is single-port laparoscopy for benign adnexal disease less painful than conventional laparoscopy? A single-center randomized controlled trial. Fertil Steril 2012;98(4):973-9.

16. Eom JM, Choi JS, Choi WJ, Kim YH, Lee JH. Does single-port laparoscopic surgery reduce postoperative pain in women with benign gynecologic disease? J Laparoendosc
Adv Surg Tech A 2013;23(12):999-1005.

17. Kim TJ, Lee YY, An JJ, Choi CH, Lee JW, Kim BG, et al. Does single-port access (SPA) laparoscopy mean reduced pain? A retrospective cohort analysis between SPA and conventional laparoscopy. Eur J Obstet Gynecol Reprod Biol 2012;162(1):71-4.

18. Fagotti A, Bottoni C, Vizzielli G, Gueli Alletti S, Scambia G, Marana E, et al. Postoperative pain after conventional laparoscopy and laparoendoscopic single site surgery (LESS) for benign adnexal disease: a randomized trial. Fertil Steril 2011;96(1):255-9 e2.

19. Cho YJ, Kim ML, Lee SY, Lee HS, Kim JM, Joo KY. Laparoendoscopic single-site surgery (LESS) versus conventional laparoscopic surgery for adnexal preservation: a randomized controlled study. Int $\mathrm{J}$ Womens Health 2012;4:85-91.

20. Kim YW, Park BJ, Kim TE, Ro DY. Single-port laparoscopic salpingectomy for surgical treatment of tubal pregnancy: comparison with multi-port laparoscopic salpingectomy. Int J Med Sci 2013;10(8):1073-8.

21. Fader AN, Escobar PF. Laparoendoscopic single-site surgery (LESS) in gynecologic oncology: technique and initial report. Gynecol Oncol 2009;114(2):157-61.

22. Yoon BS, Park H, Seong SJ, Park CT, Park SW, Lee KJ. Single-port laparoscopic salpingectomy for the surgical treatment of ectopic pregnancy. J Minim Invasive Gynecol 2010;17(1):26-9.

23. Murji A, Patel VI, Leyland N, Choi M. Single-incision laparoscopy in gynecologic surgery: a systematic review and meta-analysis. Obstet Gynecol 2013;121(4):819-28. 